\title{
Vaginoplasty Using Amniotic Membranes in Cases of Vaginal Agenesis or after Vaginectomy
}

MICHELLE NISOLLE, M.D., and JACQUES DONNEZ, M.D., Ph.D.

\begin{abstract}
Various treatments have been proposed for vaginal agenesis. The authors describe successful procedures using amniotic membranes as a graft on vaginoplasties. The amnion was not stripped from the chorion. The results showed the vagina to be well formed and of normal depth and caliber. (J GYNECOL SURG 8:25, 1992)
\end{abstract}

\section{INTRODUCTION}

$\mathbf{M}$ ALFORMATIONS OF THE VAGINA are an uncommon but serious problem. Their severity ranges from complete vaginal agenesis, with or without functioning uterus, to vaginal shortening.

The treatment of certain gynecologic malignancies, such as vaginal adenocarcinoma or vaginal severe dysplasia induced by DES, requires vaginectomy, which makes coitus impossible. In some instances, radical hysterectomy for severe cervical dysplasia must be associated with vaginectomy because of the presence of associated vaginal dysplasia. Vaginal construction or reconstruction has become a well-established method to permit or restore sexual function, and a variety of procedures have been described. The most popular method involves lining a surgically created space, either with a partial thickness skin graft ${ }^{1}$ or with amnion. ${ }^{2-10}$

In 1934, Brindeau ${ }^{2}$ used human amnion to construct the vagina for a patient with mullerian agenesis. Between 1939 and 1947, Burger ${ }^{3}$ used amnion more extensively for the same purpose. In 1973, Trelford et al. ${ }^{7}$ successfully used fetal amnion to reconstruct the vagina during anterior exenteration.

In our study, amniotic membranes have been used to line the artificially constructed vagina. The authors report their experience with the use of amniotic membranes.

\section{PATIENTS AND METHODS}

Between 1986 and 1990, amniotic membranes were used in 10 patients undergoing vaginoplasty for various etiologies, shown in Table 1.

The age of the patients ranged between 14 and 59 years.

The same technical procedure of vaginoplasty was used for the 6 patients suffering from vaginal agenesis. None of them had undergone a vaginoplasty anteriorly.

Amniotic membranes were placed into the neovagina created in cases of vaginal agenesis $(n=6)$ or into the vesicorectal space remaining after vaginectomy $(n=4)$.

Under general anesthesia, the patient was placed in the lithotomy position, and the vaginal dissection was performed. A vaginal pouch was created by blunt dissection, with the help of scissors. At the same time, a laparoscopy was carried out to confirm the diagnosis and check the blunt dissection. When hemostasis had been achieved, a vaginal mold (Fig. 1) was selected of a size just large enough to ensure firm application of the

Infertility Research Unit, Catholic University of Louvain, Brussels, Belgium. 
Table 1. Type of Vaginal Abnormality and Postoperative functional Results

\begin{tabular}{|c|c|c|c|}
\hline \multirow[b]{2}{*}{ Etiology of vaginoplasty } & \multicolumn{2}{|c|}{ Vaginal length $(\mathrm{cm})$} & \multirow[b]{2}{*}{ Functional results } \\
\hline & Preoperative & Postoperative & \\
\hline \multicolumn{4}{|l|}{ Vaginal agenesis $(n=6)$} \\
\hline \multirow[t]{6}{*}{ (Rokitansky-Kuster-Hauser syndrome) } & 1 & 7 & $+++^{a}$ \\
\hline & 1 & 7 & $+++^{c}$ \\
\hline & 1 & 7 & $+++^{c}$ \\
\hline & 1 & 8 & $+++^{c}$ \\
\hline & 1 & 7 & $+++^{c}$ \\
\hline & 3 & 8 & $+++^{c}$ \\
\hline \multicolumn{4}{|l|}{ Vaginal malignancy $(n=4)$} \\
\hline $\begin{array}{l}\text { Vaginal adenocarcinoma (post-DES } \\
\text { exposure) }(n=1)\end{array}$ & $\begin{array}{l}\text { Vaginectomy and } \\
\text { hysterectomy }\end{array}$ & 6 & $+++^{c}$ \\
\hline \multirow[t]{3}{*}{ Vaginal epidermoid carcinoma $(n=3)$} & $\begin{array}{l}\text { Vaginectomy and } \\
\text { hysterectomy }\end{array}$ & 8 & $+++^{c}$ \\
\hline & & 5 & $+++c$ \\
\hline & & 2 & $-{ }^{b}$ \\
\hline
\end{tabular}

"No sexual intercourse. Only the mold is used.

${ }^{b}$ Failure because of insufficient motivation.

"Normal vaginal capacity.

amniotic membranes, with which it was covered. The labia majora were approximated with silk sutures to keep the mold in place. A Foley catheter was inserted before the blunt dissection and left for 48 hours. After vaginectomy, simultaneously performed abdominally and perineally, the space between the bladder and the rectum was used for application of the mold.

The membranes were taken immediately postpartum from a seronegative patient who had been afebrile and whose membranes had been ruptured for less than 6 hours. In all cases, delivery occurred 3 to 6 hours before vaginoplasty. Delivery was vaginal in all cases. Elective cesarean section was not a condition for use of the membranes. The membranes are rinsed in sterile saline solution to remove all the blood and stored at $4^{\circ} \mathrm{C}$ in a saline solution (without any antibiotic). In our surgical procedure, amniotic membranes were used, and the amnion was not stripped from the chorion before its use.

The mold wrapped in amniotic membranes was inserted. Two silk sutures in the labia majora maintained the mold in position. The entire procedure was completed in 20 minutes. All patients were given antibiotics for 6 to 7 days postoperatively.

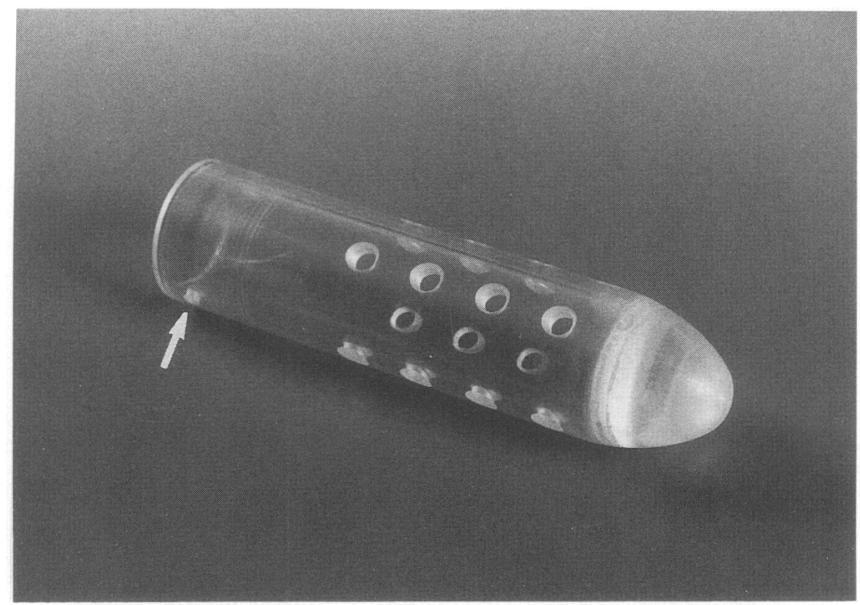

FIG. 1. Rigid vaginal mold (diameter $3.5 \mathrm{~cm}$, length 10 or $12 \mathrm{~cm}$ ). The holes allow the drainage of vaginal exudations. Two small holes (arrow) allow the mold to be fixed. 


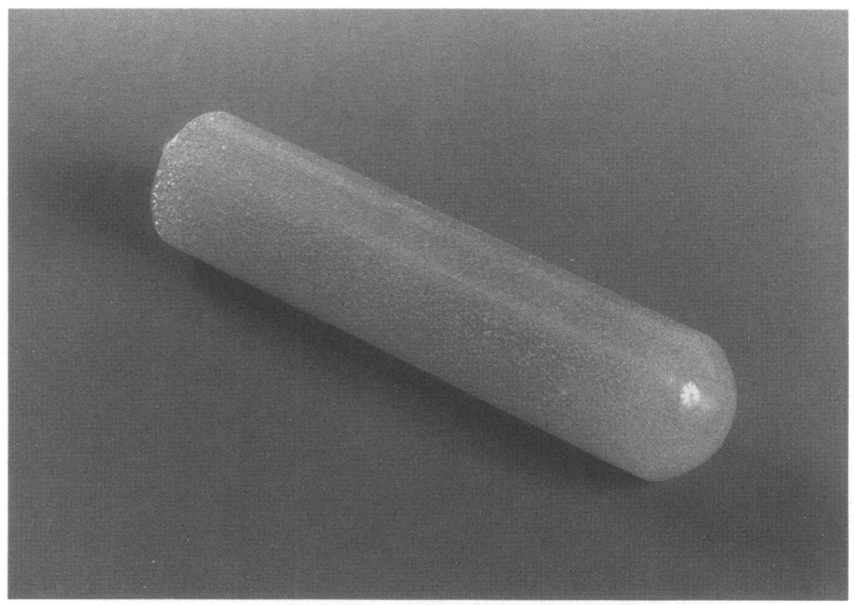

FIG. 2. Nonrigid vaginal mold (diameter $3.5 \mathrm{~cm}$, length 10 or $12 \mathrm{~cm}$ ).

The mold was removed under light sedation 7 days later, and the newly constructed vagina was inspected and cleaned. The amniotic membranes were found adherent to the vagina. A nonrigid mold (Fig. 2) was inserted, and the patient was discharged the following day and advised to refrain from sexual activity for an additional 2 weeks and to use the mold at night during this period. Dienestrol cream was used as a lubricant. The patient then was encouraged to have sexual intercourse. All patients were reviewed 2 weeks and 1 month postoperatively and then at monthly intervals.

\section{RESULTS}

All patients found the mold uncomfortable postoperatively, but all were mobile and required mild analgesia only for the mold change on the seventh day. Routine urinary catheter insertion was performed in all patients for 48 hours. All patients received prophylactic antibiotics, penicillin and metronidazole. No patient developed a urinary tract infection. At the mold change, the amniotic membranes could be seen as a distinct layer applied to the vaginal wall. At the end of the 7 days, the vaginal tunnel was covered with a smooth lining with widespread but small areas of congestion.

By the fourth week postoperatively, healthy pink vaginal epithelium was visible with, in some cases, only small areas of granulation tissue. Initial epithelialization was excellent. At the end of the 8 weeks, the vagina was found to be well formed and was of normal depth and caliber. There were no adhesions, exudate, drying, or scarring. Constant use of the mold did not result in an inflammatory reaction with formation of a granuloma in unmarried patients.

The rectum was not entered in any patient during vaginal dissection.

All patients were reviewed 2 weeks and 1 month postoperatively and then at monthly intervals. Vaginal smears at 8 weeks postoperatively showed numerous squamous epithelial cells. In all cases of vaginal agenesis, except one, epithelialization was complete, as proved by biopsy, which showed early epithelialization (at week 4-6) and mature vaginal epithelium by the end of 8 to 10 weeks (Fig. 3). In one case, granulation tissue was found, estrogen vaginal cream was not used by the patient. In cases of vaginectomy for gynecologic malignancies, epithelialization took longer, about 2 to 3 months.

The anatomic and functional results are summarized in Table 1 . The length of the vagina was found to vary from 7 to $8 \mathrm{~cm}$. All patients had greatly improved vaginal length and capacity as a result of this treatment. Excellent results were achieved in all cases except one. The oldest patient discontinued the use of the mold after leaving hospital. Two weeks postoperatively, there was complete vaginal closure. This failure could be explained by insufficient motivation of the patient. In the other cases, the vaginal tissue remained supple, with no evidence of fibrous tissue formation. Chronic granulation tissue was not observed, and vaginal shrinkage did not occur.

The final result was related directly to the motivation of the patient and her use of the mold postoperatively. To date, no long-term complications have been observed. Follow-up extends from 3 months up to 5 years. 


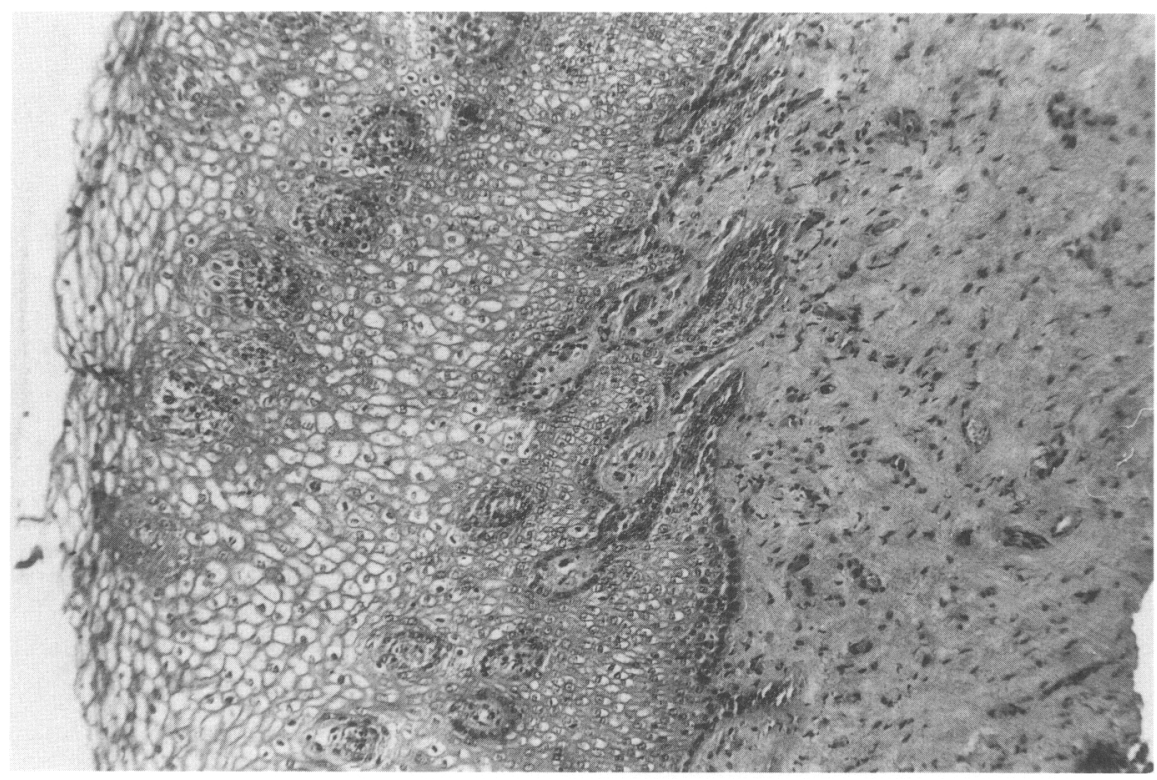

FIG. 3. Vaginal biopsy taken from the newly formed vaginal cavity 8 weeks after surgery. Mature vaginal epithelium. Gomori's trichrome. $\times 120$.

\section{DISCUSSION}

Various treatments have been described for vaginal agenesis. Frank ${ }^{11}$ reported graduated vaginal dilatation, but this technique has given good results in less than $50 \%$ of patients. Williams ${ }^{12}$ described the method of a turned-in labial flap. Although the procedure did not require any graft, no satisfactory results were reported. Indeed, the vaginal axis was often ill placed, and difficulties at the time of micturition and repeated urinary tract infections were observed.

Creating a tunnel for congenital absence of the vagina is a step that is common to all surgical procedures. The use or nonuse of a graft could be discussed, and if a graft is to be used, which tissue is best—skin, intestine, or amnion.

The use of cecal or sigmoid bowel segments was reported by Baldwin ${ }^{13}$ in 1904 . Though some authors claimed good results, this method is a major surgical procedure with significant morbidity and mortality. Turner-Warwick and Kirby ${ }^{14}$ have reported successful reconstruction of the vagina with the colocecum without serious surgical complication, but profuse secretions, persistent unpleasant odor, and ulceration of the mucosal surface could be the major side effects.

Wharton ${ }^{15}$ devised an operation based on the remarkable regenerative potential of granulation tissue in the vaginal canal. To keep the space patent, a condom-covered mold was used. McIndoe and Bannister ${ }^{1}$ modified Wharton's operation by the additional step of transplanting a split-thickness skin graft into the newly formed vaginal cavity held in place by a vaginal mold. The great variations in success rate, high incidence of postoperative infection, necrosis of the skin graft, and scarring, however, made it less acceptable. Moreover, the patient suffers considerable discomfort from the donor skin site, which may remain visible.

Myocutaneous flaps have been used by several authors. The gracilis myocutaneous flap has become very popular in recent years, ${ }^{16-19}$ but a serious disadvantage is the precarious vascularity of the flaps. In the series of McCraw et al. ${ }^{20}$ of 22 patients, 6 suffered a totally catastrophic loss of the flap. The rectus abdominis flap is another popular flap, but the singular complaint about it is the large abdominal donor-site defect, ${ }^{21}$ and the operative time is long. The neurovascular pudendal thigh flap procedure is a feasible one that also can be used reliably to reconstruct the vagina. The results from all the techniques with flaps described partial flap loss and necrosis in an unacceptable failure rate. Moreover, such dissections caused a major skin scar and could be indicated only for vaginal reconstruction after pelvectomy for pelvic cancer, when subsequent irradiation must be carried out.

To overcome these difficulties, amnion alone with the clean mesenchymal surface placed toward the host was used by several authors (Brindeau, ${ }^{2}$ Burger, ${ }^{3}$ Trelford et al., ${ }^{6}$ and Dhall ${ }^{9}$ ). Dino et al. ${ }^{23}$ suggested 
sterilizing amniotic membranes. Trelford et al..$^{5.7}$ found that membranes stored at $4^{\circ} \mathrm{C}$ in $0.5 \mathrm{~N}$ saline with antibiotics were sterile at the end of 48 hours.

In our study, amniotic membranes were taken immediately postpartum $(<6$ hours). Saline solution with antibiotics was never used. Membranes were rinsed only in sterile physiologic solution $(\mathrm{NaCl} 0.9 \%)$.

Faulk et al. ${ }^{24}$ have demonstrated microscopic evidence of new vessel formation and suggested that an angiogenic factor is produced by amnion. There is no problem with immune rejection because amnion does not express histocompatibility antigens, and Akle et al. ${ }^{25}$ found no evidence of tissue rejection when amnion was implanted subcutaneously in volunteers. Tancer et al. ${ }^{8}$ Dhall, ${ }^{9}$ and Ashworth et al. ${ }^{10}$ have reported successful procedures using amnion as a graft on vaginoplasties. Removal of the more antigenic chorion has been suggested to contribute to the successful use of the amnion. In the present study, however, the amnion was not stripped from the chorion. Our results show the vagina to be well formed and of normal depth and caliber. There was no problem of immune rejection. Sexual intercourse was reported to be satisfactory in all cases. Vaginal smears and vaginal biopsy specimens were taken at follow-up visits. Vaginal epithelium was present by 8 to 10 weeks.

In conclusion, amniotic membranes readily available, easily stored, and inexpensive can be used without sterilization as a graft for vaginal reconstruction. The amniotic membranes adhere firmly, protect the underlying granulation, and facilitate epithelialization. Hospitalization is considerably reduced, and major skin defects occurring after myocutaneous flap reconstruction are avoided. No postoperative dilatation is needed once normal sexual intercourse is resumed.

\section{REFERENCES}

1. McIndoe AH, Bannister JE. An operation for the cure of congenital absence of the vagina. J Obstet Gynaecol Br Emp 1938;45:490

2. Brindeau A. Création d'un vagin artificiel à l'aide des membranes ovulaires d'un oeuf à terme. Gynecol Obstet (Paris) 1934;29:385.

3. Burger K. Weitere Erfahrungen über die kunstliche Scheidenbildung mit Eihäuten. Zentralbl Gynaekol 1947;69:1153.

4. Trelford JD, Hanson FW, Anderson DG. Amniotic membrane as a living surgical dressing in human patients. Oncology 1973;28:358.

5. Trelford JD, Anderson D, Hanson F, Mendel V. Amniotic membrane used for radical vulvectomies. Obstet Gynecol Observ 1973;12:1.

6. Trelford JD, Hanson FW, Anderson DS. The feasibility of making an artificial vagina at the time of anterior exenteration. Oncology 1973;28:398.

7. Trelford-Sauder M, Trelford JD, Matolo NM. Replacement of the peritoneum with amnion following pelvic exenteration. Surg Gynecol Obstet 1977;145:699.

8. Tancer ML, Katz M, Veridiano NP. Vaginal epithelialization with human amnion. Obstet Gynecol 1979;54:345.

9. Dhall K. Amnion graft for treatment of congenital absence of the vagina. Br J Obstet Gynaecol 1984;91:279.

10. Ashworth MF, Morton KE, Dewhurst J, Lilford RJ, Bates RG. Vaginoplasty using amnion. Obstet Gynecol 1986;67:443.

11. Frank RT. The formation of an artificial vagina without operation. Am J Obstet Gynecol 1938;35:1053.

12. Williams EA. Congenital absence of the vagina-A simple operation for its relief. J Obstet Gynaecol Br Commonw 1964;71:511.

13. Baldwin JF. The formation of an artificial vagina by intestinal transplantation. Ann Surg 1904;40:398.

14. Turner-Warwick R, Kirby RS. The construction and reconstruction of the vagina with the colocecum. Surg Gynecol Obstet 1990;170:132.

15. Wharton LR. A simple method of constructing a vagina. Ann Surg 1938;107:842.

16. Heath PM, Woods JE, Podratz KC, Arnold PG, Irons GB. Gracilis myocutaneous vaginal reconstruction. Mayo Clin Proc 1984;59:21.

17. Lagasse LD, Berman ML, Watring WG, Ballon SC. The gynecologic oncology patient: Restoration of function and prevention of disability. In: McGowan L, ed. Gynecologic oncology. New York: Appleton-Century-Crofts, 1978:398. 
18. Lacey PM, Morrow CP. Myocutaneous vaginal reconstruction. In: Morrow CP, Smart GE, eds. Gynecologic oncology. Berlin: Springer-Verlag, 1986:255.

19. Wheeless CR. Vulvar-vaginal reconstruction. In: Coppleson M, ed. Gynecologic oncology: Fundamental principles and clinical practice. Edinburgh: Churchill Livingstone, 1981;2:933.

20. McCraw JB, Massey FM, Shanklin KD, Horton CE. Vaginal reconstruction with gracilis myocutaneous flaps. Plast Reconstr Surg 1976;58:176.

21. Gordon RT, Thomas GD. Vaginal and pelvic reconstruction with distally based rectus abdominis myocutaneous flaps. Plast Reconstr Surg 1988;71.

22. Wee TK, Joseph VT. A new technique of vaginal reconstruction using neurovascular pudendal-thigh flaps: A preliminary report. Plast Reconstr Surg 1989; 701.

23. Dino BR, Eufemio GG, DeVilla MS. Human amnion: The establishment of an amnion bank and its practical applications in surgery. J Philippine Med Assoc 1966;42:357.

24. Faulk WP, Matthews R, Stevens PJ, et al. Human amnion as an adjunct in wound healing. Lancet 1980;1:1156.

25. Akle CA, Adinolfi M, Welsh KI, et al. Immunogenicity of human amniotic epithelial cells after transplantation into volunteers. Lancet 1980;2:1003.

Address reprint requests to:

Professor J. Donnez

Head of Department

Catholic University of Louvain

Avenue Hippocrate 10

B-1200 Brussels

Belgium 